\title{
CONTINGENT PROTECTION AS BETTER INSURANCE
}

\author{
Ronald D. Fischer \\ Thomas J. Prusa \\ Working Paper 6933 \\ http://www.nber.org/papers/w6933 \\ NATIONAL BUREAU OF ECONOMIC RESEARCH \\ 1050 Massachusetts Avenue \\ Cambridge, MA 02138 \\ February 1999
}

Fischer wishes to thank the Dirección de la Facultad de Ciencias Físcias Matemáticas for the financial support of a research grant. Fischer also thanks Rutgers University for its hospitality. We wish to thank Avinash Dixit, Jonathan Eaton, Gene Grossman, and Rich McLean for their comments and suggestions. The views expressed here are those of the author and do not reflect those of the National Bureau of Economic Research.

(1) 1999 by Ronald D. Fischer and Thomas J. Prusa. All rights reserved. Short sections of text, not to exceed two paragraphs, may be quoted without explicit permission provided that full credit, including ${ }^{(0)}$ notice, is given to the source. 
Contingent Protection as Better Insurance

Ronald D. Fischer and Thomas J. Prusa

NBER Working Paper No. 6933

February 1999

JEL No. F13

\begin{abstract}
We formalize the notion that GATT exceptions such as antidumping and escape clause actions can act as insurance for import competing sectors affected by adverse price shocks. We use a general equilibrium model with several import competing sectors and assume incomplete markets so that agents cannot contract insurance. We show that these measures are superior to uniform tariffs as insurance mechanisms. Moreover, we demonstrate that the optimal uniform policy may not involve a tariff at all, but rather might entail an export tax. We also show that a tax cum subsidy policy (i.e., taxing all sectors in order to subsidize the shocked sector) improves welfare.
\end{abstract}

\author{
Ronald D. Fischer \\ Depto Ingeniería Industrial \\ U. de Chile \\ República 701 \\ Casilla 2777 \\ Santiago, Chile \\ rfischer@dii.uchile.cl
}

Thomas J. Prusa

Department of Economics

Rutgers University

New Brunswick, NJ 08901-1248

and NBER

prusa@econ.rutgers.edu 


\section{Introduction}

Thanks primarily to the tariff reductions negotiated under the auspices of the GATT and WTO, international trade is likely as unfettered by restrictions as any other time in history. While the gains from free trade are widely recognized, it is also well known that openness makes economies more vulnerable to injury from adverse trade shocks. GATT founders were cognizant that injured import competing groups might use such shocks as an excuse to renege on GATT agreements; for that reason exceptions to tariff obligations were provided within the GATT. These exceptions allow governments to protect the injured sector while not abandoning the tariff liberalization achieved in other sectors. ${ }^{1}$

GATT exceptions allow governments to take actions in response to imports which are deemed to have harmed the domestic competing industry. If injury is caused by "fair" trade (e.g., an increase in imports due to tariff reductions), a government can invoke the escape clause to restrain imports; if injury is caused by "unfair" trade (e.g., dumping or government subsidization of imports), the policy response is antidumping or countervailing duties. Dam (1970) points out that these exceptions have been included in every GATT agreement. Moreover, he argues that the inclusion of these exceptions was crucial for the success of the early GATT rounds. His view is that exceptions greatly increased the number of sectors where tariffs were liberalized by diffusing domestic political opposition toward trade liberalization. In a sense, exceptions offered the promise of insurance for sectors injured by the liberalization.

Clearly then, for many years policy-makers have taken for granted that trade policy can act as insurance. However, the notion that trade policy can act as insurance was not formalized until Eaton and Grossman (1985). ${ }^{2}$ In their model there is a single import competing sector and single export sector. The import competing sector is subject to price shocks. The goods are produced with two factors; one factor (labor) can be allocated after the price shock is realized while the other factor (capital) can only be allocated before the terms of trade are realized. Eaton and Grossman (EG) demonstrate that a tariff can raise ex ante welfare if insurance markets are incomplete.

EG's insight has spurred a number of other papers, most notably those by Staiger and Tabellini (1987) and Dixit (1987, 1989a, 1989b). These related papers also assume that markets are incomplete and that factors are not completely mobile ex post. Staiger and Tabellini use the basic EG framework to examine the time consistency of tariff protection. While EG and Staiger and Tabellini were willing to leave implicit the reasons for the incompleteness of insurance markets Dixit argues that the source of the incompleteness can be important. For instance, he shows that when the market failure is explicitly tied to adverse selection or moral hazard the laissez-faire equilibrium may be Pareto optimal. Following EG's approach, we will leave the precise source of the market failure implicit, but note that unobservable actions and outcomes are not the only source of market

\footnotetext{
${ }^{1}$ See Jackson (1969) for a description of the legal foundations for exceptions. Staiger (1995) discusses some economic issues relating to GATT rules and institutions.

${ }^{2}$ The idea that trade policy might act as insurance was informally discussed for many years, e.g., Corden (1974) and Baldwin (1982).
} 
incompleteness. Rather, the transaction costs of insuring agents against trade shocks are surely quite large and will likely preclude complete insurance. In addition, trade shocks may well give rise to bankruptcy concerns, implying that markets will likely be at least partially incomplete. Finally, there might be other distortions in the economy that preclude complete insurance. ${ }^{3}$

We believe, however, the EG model is not well suited to study GATT exceptions for at least two reasons. First, GATT MNF tariffs are typically negotiated years in advance and thus are very difficult to be levied in a contingent fashion. GATT exceptions, on the other hand, are precisely designed to be levied after the trade shock. Second, and the more troubling concern, exceptions like antidumping and the escape clause are sector specific protection. With a single import-competing sector, EG's model can not adequately characterize the conditions when sector specific protection is desirable. In their model the tariff is levied on all import competing sectors; therefore their paper is better interpreted as formalizing the effect of a uniform tariff.

In this paper we develop a model that allows us to better answer the question of whether GATT exceptions can act as insurance. With the EG model serving as the foundation for our analysis, we allow for multiple import competing sectors which are subject to sector specific price shocks. This allows us to understand and contrast the distortions created across sectors. As in the EG paper, we assume capital is immobile ex post and markets are incomplete. We show that GATT exceptions raise welfare by providing insurance.

In addition, we compare the efficacy of contingent measures with the traditional "across the board" tariff protection ala EG. We show that these policies dominate uniform tariffs. In contrast with EG, we find that the optimal uniform policy may involve export taxes. The difference lies in the fact that in our somewhat more general model only one sector benefits from the imposition of a uniform tariff while the other sector is worse off. Thus, when it comes to uniform policies we find that what is good for the goose is not good for the gander.

Thus, our model provides a theoretical foundation for the notion that GATT exceptions can provide insurance. Given the unprecedented use of GATT exceptions - in particular antidumping actions - during the past twenty years, many question whether insurance is the motivation for many of the actions (Bhagwati, 1988; Finger, 1993; Krueger, 1995). ${ }^{4}$ Briefly stated, the concern is that antidumping procedures allow investigations to be conducted when there is little evidence of injury or unfair actions. Given the apparent capture of antidumping by protectionist interests, we also examine whether an alternative policy might could also serve as insurance. In particular, we consider a policy wherein the adversely affected sector is offered a subsidy which is financed by taxes on the non-affected sectors; we find that this "tax and subsidize" policy also increases welfare. This suggests that it is possible to design alternative policies that have the beneficial risk-sharing

\footnotetext{
${ }^{3}$ Consider the case where insurance against market shocks is expensive, due to the existence of a monopoly in insurance. The first best would be to eliminate the monopoly, in which case it might not be necessary to have contingent protection. If this is impossible, contingent protection can be used as a second best way to avoid the cost of not being able to insure against trade shocks.

${ }^{4}$ Staiger and Wolak (1994) find that many U.S. antidumping complaints are not primarily aimed at winning duties, but rather are at hindering the foreign rival during the investigation (in their terminology, many industries are "process filers").
} 
properties of current GATT exceptions but without their weaknesses.

\section{The Model}

We consider a three sector model of a small open economy facing stochastic international prices. ${ }^{5}$ The goods are $X, Y^{1}, Y^{2}$; all are consumed domestically. We also assume that in all states of the world all three goods are produced domestically. Following EG we assume that at the time capital must be allocated between productive sectors the terms of trade are unknown. In contrast, labor can move between sectors after the uncertainty is resolved and after the trade policy is implemented.

We assume that good $X$, the export good, is produced under constant returns to scale using only labor. We let $X$ be the numeraire good; to simplify we assume that $X=G\left(L^{X}\right)=L^{X}$, so $w=1$. The other two goods are imported and are produced using a CRS technology with capital and labor. The outputs of the import competing goods in state $s$ are given by

$$
Y^{1 s}=F^{1}\left(K^{1}, L^{1 s}\right), \quad Y^{2 s}=F^{2}\left(K^{2}, L^{2 s}\right),
$$

where $K^{i}$ and $L^{i s}$ denote the amount of capital and labor employed in the production of good $i$ in state $s$. The production functions are quasi-concave and twice differentiable.

Each household has one unit of labor and $k$ units of non-divisible capital. Each household must allocate its capital to one sector. We assume that total endowment of labor is one $(L=1)$ implying that $K=k$ is total capital. Full employment implies $L^{X s}+L^{1 s}+L^{2 s}=1$ and $K^{1}+K^{2}=K=k$. Let $\lambda^{i} \equiv K^{i} / K=K^{i} / k$ be the proportion of households that allocate their capital to sector $i$, so that $K^{i}=\lambda^{i} K$. Since we can associate the households to the sector in which they invest, it follows that there are $\lambda^{1}$ households in sector 1 and $\lambda^{2}=1-\lambda^{1}$ households in sector 2 .

Let $\mathcal{P}^{i s}$ be the world price of good $i=1,2$ in state $s$. The domestic price can be written as $p^{i s}=\left(1+t^{i s}\right) \mathcal{P}^{i s}$, where $t^{i s}$ denotes the ad valorem tariff for good $i$ in state $s$. Let $C^{i j s}$ be the consumption of good $i$ by households invested in sector $j$ in state $s$. The value of imports are defined as

$$
M^{s}=\mathcal{P}^{1 s} M^{1 s}+\mathcal{P}^{2 s} M^{2 s}=\mathcal{P}^{1 s}\left(\lambda^{1} C^{11 s}+\lambda^{2} C^{12 s}-F^{1}\right)+\mathcal{P}^{2 s}\left(\lambda^{1} C^{21 s}+\lambda^{2} C^{22 s}-F^{2}\right) .
$$

The return to a household from her capital investment in sector $i$ is

$$
r^{i s}=p^{i s} F_{K}^{i}\left(K^{i}, L^{i s}\right),
$$

where the subscript $K$ indicates partial derivative. The income accruing to the typical household

\footnotetext{
${ }^{5}$ The results can be easily extended to the case of $n$ import competing sectors.
} 
in industry $i$ is

$$
y^{i s}=p^{i s} F_{K}^{i}\left(K^{i}, L^{i s}\right) k+w+T^{s},
$$

where $T^{s}$ denotes tariff revenue in state $s$. We assume the revenue is distributed equally among households in a lump sum fashion.

There are three states of nature. State $s$ occurs with probability $\pi^{s}, s \in \mathcal{S}=\{A, B, C\}$. In state $A(B)$ sector $1(2)$ receives a negative price shock; in state $C$ neither import competing sector receives a shock. Throughout much of the paper we will suppress the superscript $s$ unless doing so leads to confusion.

The key question we are concerned with is the welfare effects of tariff policy. Given the small country assumption, free trade is the optimal policy unless there are terms of trade shocks. In light of the uncertainty trade policy may now act as insurance and hence raise welfare. The desirability of such a policy depends in part on the nature of the tariff. In section 3 we examine the benchmark case when the government sets a uniform tariff. In this case $t^{1}=t^{2}=t$ and tariff revenue is simply $T=t M$. In section 4 we consider sector specific contingent tariffs - such as antidumping and escape clauses. In this scenario the tariff is levied only on the injured sector, implying case tariff revenue is $T=t^{i} \mathcal{P}^{i} M^{i}$.

Letting $V^{i s} \equiv V\left(y^{i s}, p^{1 s}, p^{2 s}\right)$ denote the indirect utility function of a type $i$ household in state $s$ we can define welfare as ${ }^{6}$

$$
W \equiv \sum_{s \in \mathcal{S}} \pi^{s} W^{s}=\sum_{s \in \mathcal{S}} \pi^{s}\left(\lambda^{1} V^{1 s}+\lambda^{2} V^{2 s}\right)
$$

Finally we assume that ex ante an investment in each sector produces the same expected utility, implying

$$
\sum_{s \in \mathcal{S}} \pi^{s}\left(V^{1 s}-V^{2 s}\right)=0
$$

\section{Uniform tariff policy}

We begin by considering the effect of imposing a uniform tariff in case of a negative shock (and no tariff if there is no shock). Since we believe that anticipated policies are of greater interest, we assume that all agents internalize the existence of the uniform tariff. ${ }^{7}$

\footnotetext{
${ }^{6}$ Good $X$ also enters the utility function, but since it is the numeraire good it is convenient if we suppress it in the indirect utility function.

${ }^{7}$ The effect of a uniform tariff when the tariff is anticipated is similar. This is somewhat surprising since in general the tariff alters the return in each of the possible states of nature, which in turn means that the allocation of capital
} 
For notational convenience we will use dot notation to denote derivatives with respect to the tariff, e.g., $\dot{y} \equiv d y / d t, \dot{M} \equiv d M / d t$, etc. The following result will useful in deriving the main welfare result.

Lemma 1 The effect of an anticipated uniform tariff on sector $i$ income is

$$
\frac{d y^{i}}{d t} \equiv \dot{y}^{i}=\frac{\mathcal{P}^{i} F^{i}}{\lambda^{i}}+M+t \dot{M}, \quad i=1,2 .
$$

Proof: First note that

$$
\dot{w}=\mathcal{P}^{i} F_{L}^{i}+p^{i} F_{L K}^{i} \dot{K}^{i}+p^{i} F_{L L}^{i} \dot{L}^{i}=0, \quad i=1,2 .
$$

Differentiating equation (2) and solving yields

$$
\begin{aligned}
& \dot{y}^{i}= \mathcal{P}^{i} F_{K}^{i} k+p^{i} F_{K K}^{i} k \dot{K}^{i}+p^{i} F_{K L}^{i} k \dot{L}^{i}+M+t \dot{M} \\
&= {\left[\mathcal{P}^{i} F_{K}^{i} k+\mathcal{P}^{i} F_{L}^{i} \frac{L^{i}}{\lambda^{i}}\right]+\left[p^{i} F_{K K}^{i} k \dot{K}^{i}+p^{i} F_{L K}^{i} \dot{K}^{i} \frac{L^{i}}{\lambda^{i}}\right] } \\
& \quad+\left[p^{i} F_{K L}^{i} k \dot{L}^{i}+p^{i} F_{L L}^{i} \dot{L}^{i} \frac{L^{i}}{\lambda^{i}}\right]+M+t \dot{M} \\
&= \frac{\mathcal{P}^{i}}{\lambda^{i}}\left[F_{K}^{i} K^{i}+F_{L}^{i} L^{i}\right]+\frac{p^{i} \dot{K}^{i}}{\lambda^{i}}\left[F_{K K}^{i} K^{i}+F_{L K}^{i} L^{i}\right] \\
& \quad+\frac{p^{i} \dot{L}^{i}}{\lambda^{i}}\left[F_{K L}^{i} K^{i}+F_{L L}^{i} L^{i}\right]+M+t \dot{M} \\
&=\frac{\mathcal{P}^{i} F^{i}}{\lambda^{i}}+M+t \dot{M},
\end{aligned}
$$

where we have used Euler's theorem three times.

Q.E.D.

Lemma 2 The effect of a small uniform tariff on welfare in state $s$ is given by

$$
\left.\left.\frac{d W^{s}}{d t}\right|_{t=0} \equiv \dot{W}^{s}\right|_{t=0}=\lambda^{1} \lambda^{2} \pi^{s}\left(V_{y}^{1 s}-V_{y}^{2 s}\right)\left\{\left(\dot{y}^{1 s}-\dot{y}^{2 s}\right)+\mathcal{P}^{1 s}\left(C^{12 s}-C^{11 s}\right)+\mathcal{P}^{2 s}\left(C^{22 s}-C^{21 s}\right)\right\}
$$

Proof: Consider the effect of a tariff on welfare in state $s$ :

could depend on whether the tariff is anticipated. In the case of a uniform tariff, however, this effect does not exist. This rather surprising result is explained by the fact that the relative price of the import goods $p^{1} / p^{2}$, remains the same with or without the tariff. Given that ex ante investment in each sector provides the same expected utility, we find that anticipated and unanticipated protection has the same effect on income. 


$$
\dot{W}^{s}=\pi^{s} \lambda^{1}\left[V_{y}^{1 s} \dot{y}_{1}^{s}+V_{1}^{1 s} \mathcal{P}^{1 s}+V_{2}^{1 s} \mathcal{P}^{2 s}\right]+\pi^{s} \lambda^{2}\left[V_{y}^{2 s} \dot{y}_{2}^{s}+V_{1}^{2 s} \mathcal{P}^{1 s}+V_{2}^{2 s} \mathcal{P}^{2 s}\right]
$$

where we have denoted $d V / d p^{i} \equiv V_{i}$. Using Roy's identity, we get

$$
\dot{W}^{s}=\lambda^{1} V_{y}^{1 s}\left[\dot{y}_{1}^{s}-\mathcal{P}^{1 s} C^{11 s}-\mathcal{P}^{2 s} C^{21 s}\right]+\lambda^{2} V_{y}^{2 s}\left[\dot{y}_{2}^{s}-\mathcal{P}^{1 s} C^{12 s}-\mathcal{P}^{2 s} C^{22 s}\right]
$$

We now use Lemma 1 to get (we now suppress the superscript $s$ to simplify the notation)

$$
\begin{aligned}
\dot{W}^{s}= & \pi^{s} \lambda^{1} V_{y}^{1}\left\{\mathcal{P}^{1} F^{1} / \lambda^{1}+t \dot{M}+M-\mathcal{P}^{1} C^{11}-\mathcal{P}^{2} C^{21}\right\} \\
& +\pi^{s} \lambda^{2} V_{y}^{2}\left\{\mathcal{P}^{2} F^{2} / \lambda^{2}+t \dot{M}+M-\mathcal{P}^{1} C^{12}-\mathcal{P}^{2} C^{22}\right\} .
\end{aligned}
$$

Using the import equation (1) we have

$$
M-\mathcal{P}^{1} C^{11}-\mathcal{P}^{2} C^{21}=\mathcal{P}^{1}\left[\lambda^{2}\left(C^{12}-C^{11}\right)-F^{1}\right]+\mathcal{P}^{2}\left[\lambda^{1}\left(C^{22}-C^{21}\right)-F^{2}\right]
$$

and a corresponding expression for $M-\mathcal{P}^{1} C^{12}-\mathcal{P}^{2} C^{22}$. Substituting these into (8) yields

$$
\begin{aligned}
\dot{W}^{s}= & \pi^{s} \lambda^{1} V_{y}^{1}\left\{\mathcal{P}^{1}\left(F^{1} / \lambda^{1}\right)+t \dot{M}+\mathcal{P}^{1}\left[\lambda^{2}\left(C^{12}-C^{11}\right)-F^{1}\right]+\mathcal{P}^{2}\left[\lambda^{2}\left(C^{22}-C^{21}\right)-F^{2}\right]\right\} \\
& +\pi^{s} \lambda^{2} V_{y}^{2}\left\{\mathcal{P}^{2}\left(F^{2} / \lambda^{2}\right)+t \dot{M}+\mathcal{P}^{1}\left[\lambda^{1}\left(C^{11}-C^{12}\right)-F^{1}\right]+\mathcal{P}^{2}\left[\lambda^{1}\left(C^{21}-C^{22}\right)-F^{2}\right]\right\} .
\end{aligned}
$$

Using Lemma 1 note that

$$
\dot{y}^{1}-\dot{y}^{2}=\frac{\lambda^{2} \mathcal{P}^{1} F^{1}-\lambda^{1} \mathcal{P}^{2} F^{2}}{\lambda^{1} \lambda^{2}} .
$$

Substituting this expression gives

$$
\begin{aligned}
\dot{W}^{s}= & \pi^{s} \lambda^{1} \lambda^{2} V_{y}^{1}\left\{\left(\dot{y}^{1}-\dot{y}^{2}\right)+\left(t \dot{M} / \lambda^{2}\right)+\mathcal{P}^{1}\left(C^{12}-C^{11}\right)+\mathcal{P}^{2}\left(C^{22}-C^{21}\right)\right\} \\
& +\pi^{s} \lambda^{1} \lambda^{2} V_{y}^{2}\left\{\left(\dot{y}^{2}-\dot{y}^{1}\right)+\left(t \dot{M} / \lambda^{1}\right)+\mathcal{P}^{1}\left(C^{11}-C^{12}\right)+\mathcal{P}^{2}\left(C^{21}-C^{21}\right)\right\},
\end{aligned}
$$

from which we obtain 


$$
\begin{aligned}
\dot{W}^{s}= & \lambda^{1} \lambda^{2} \pi^{s}\left(V_{y}^{1 s}-V_{y}^{2 s}\right)\left\{\left(\dot{y}^{1 s}-\dot{y}^{2 s}\right)+\mathcal{P}^{1 s}\left(C^{12 s}-C^{11 s}\right)+\mathcal{P}^{2 s}\left(C^{22 s}-C^{21 s}\right)\right\} \\
& +t \dot{M} \lambda^{1} \lambda^{2} \pi^{s}\left(\frac{V_{y}^{1 s}}{\lambda^{2}}+\frac{V_{y}^{2 s}}{\lambda^{1}}\right)
\end{aligned}
$$

where we again use superscript $s$ to denote the state. Evaluating at $t=0$, we obtain the desired expression.

Q.E.D.

Lemma 2 allows us to evaluate the welfare effect of a uniform tariff. Suppose there is a negative price shock to sector 1 (state $A$ ). We have that $y^{1 A}<y^{2 A}$, hence $\left(V_{y}^{1 A}-V_{y}^{2 A}\right)>0$ because of diminishing marginal utility. We can also sign the consumption terms if the importables are not inferior (both terms are positive). Note however that the term $\dot{y}^{1 A}-\dot{y}^{2 A}$ is negative (from (9)). Therefore we cannot sign the overall expression (10). The same ambiguity exists in state $B$. Since the optimal policy in state $C$ is free trade, we must conclude that

Proposition 1 A small uniform tariff has an ambiguous effect on welfare, i.e.,

$$
\left.\frac{d W}{d t}\right|_{t=0} \gtreqless 0 .
$$

Proposition 1 contrasts with EG's (1985) finding that a small tariff raises welfare when there are negative import price shocks. The difference lies in the fact that our model allows for multiple import competing goods and while a uniform tariff carries benefits to the injured sector (as in EG) it has a negative effect on the other import competing sector. This result helps explain why we do not observe countries using uniform tariff policies to safeguard domestic industries from sector specific terms of trade shocks.

\section{A sector specific tariff}

We now consider the case when a sector specific tariff is imposed whenever there is a shock to a particular sector. We will assume that the government reacts by imposing tariff $t^{i}$ on good $i$ when there is a shock to that sector. All other sectors remain unprotected. Formally, the domestic price of good $i$ in state $s$ is $p^{i s}=\mathcal{P}^{i s}\left(1+t^{i s}\right)$ and

$$
t^{i s}= \begin{cases}t^{i}>0 & \text { if } i=1 \text { and } s=A \text { or if } i=2 \text { and } s=B \\ 0 & \text { otherwise. }\end{cases}
$$

A sector-specific tariff has two effects: an ex post effect on the allocation of labor once the state and the applicable tariff are known, and an ex ante effect on the allocation of capital between 
sectors. For instance, suppose we are in state $A$. An increase in the state $A$ tariff raises the attractiveness of sector 1 , since the bad state turns out to be not so bad (since the tariff raises the expected return to sector 1 capital). This implies that more capital will be invested in sector 1 (and less in other sectors). Hence, a state contingent tariff will have an effect on the capital stocks in all states, in contrast to the case of a uniform tariff.

Without loss of generality we will study the welfare effect of a state $A$ contingent tariff (i.e., a tariff $\left.t^{1}>0\right)$. All the results are directly applicable to a state $B$ contingent tariff. Differentiating equation (3) with respect to a state $A$ contingent tariff leads to

$$
\frac{d W}{d t^{1}}=\sum_{s \in \mathcal{S}} \pi^{s}\left\{\left(\lambda^{1} \frac{\partial V^{1 s}}{\partial t^{1}}+V^{1 s} \frac{d \lambda^{1}}{d t^{1}}\right)+\left(\lambda^{2} \frac{\partial V^{2 s}}{\partial t^{1}}+V^{2 s} \frac{d \lambda^{2}}{d t^{1}}\right)\right\}
$$

The following lemma will be useful in solving for the effect of a state contingent tariff.

\section{Lemma 3}

$$
\sum_{s \in \mathcal{S}} \pi^{s}\left(V^{1 s} \frac{d \lambda^{1}}{d t^{1}}+V^{2 s} \frac{d \lambda^{2}}{d t^{1}}\right)=0
$$

Proof: From $K^{1}+K^{2}=K$ it follows that

$$
\frac{d K^{1}}{d t^{1}}=-\frac{d K^{2}}{d t^{1}}
$$

This implies

$$
\frac{d \lambda^{1}}{d t^{1}}=\frac{d \lambda^{1}}{d K^{1}} \frac{d K^{1}}{d t^{1}}=-\frac{1}{k} \frac{d K^{2}}{d t^{1}}
$$

Substituting yields

$$
\begin{aligned}
\sum_{s \in \mathcal{S}} \pi^{s} \sum_{i=1}^{2} V^{i s} \frac{d \lambda^{i}}{d t^{1}} & =\sum_{s \in \mathcal{S}} \pi^{s}\left[\left(V^{2 s}-V^{1 s}\right)(1 / k) \frac{d K^{2}}{d t^{1}}\right] \\
& =(1 / k) \frac{d K^{2}}{d t^{1}} \sum_{s \in \mathcal{S}} \pi^{s}\left(V^{2 s}-V^{1 s}\right)=0
\end{aligned}
$$

where the last equality follows from (4).

Q.E.D. 
Lemma 4 The change in income due to a state A contingent tariff is

$$
\begin{aligned}
\dot{y}^{1 A} & =\frac{\mathcal{P}^{1 A} F^{1}}{\lambda^{1}}+M^{1 A}+t^{1} \dot{M}^{1 A} \\
\dot{y}^{2 A} & =M^{1 A}+t^{1} \dot{M}^{1 A}
\end{aligned}
$$

Proof: From the wage equation $1=w=p^{i A} F_{L}^{i}, i=1,2$, we have that

$$
\dot{w}=0=\mathcal{P}^{1 A} F_{L}^{1}+p^{1 A} F_{L L}^{1} \dot{L}^{1}+p^{1 A} F_{L K}^{1} \dot{K}^{1}=p^{2 A} F_{L L}^{2} \dot{L}^{2}+p^{2 A} F_{L K}^{2} \dot{K}^{2}
$$

Differentiating (2) it follows that the change in income in state $A$ is

$$
\begin{aligned}
\dot{y}^{1 A}= & \mathcal{P}^{1 A} F_{K}^{1} k+p^{1 A} F_{K K}^{1} \dot{K}^{1} k+p^{1 A} F_{K L}^{1} \dot{L}^{1} k+t^{1} \dot{M}^{1 A}+M^{1 A} \\
= & \mathcal{P}^{1 A} F_{K}^{1} k+p^{1 A} F_{K K}^{1} \dot{K}^{1} k+p^{1 A} F_{K L}^{1} \dot{L}^{1} k+t^{1} \dot{M}^{1 A}+M^{1 A} \\
& \quad+\left(p^{1 A} F_{L L}^{1} \dot{L}^{1} \frac{L^{1}}{\lambda^{1}}-p^{1 A} F_{L L}^{1} \dot{L}^{1} \frac{L^{1}}{\lambda^{1}}\right)+\left(p^{1 A} F_{K L}^{1} \dot{K}^{1} \frac{L^{1}}{\lambda^{1}}-p^{1 A} F_{K L}^{1} \dot{K}^{1} \frac{L^{1}}{\lambda^{1}}\right) \\
= & \left(\mathcal{P}^{1 A} F_{K}^{1} k+\mathcal{P}^{1 A} F_{L}^{1} \frac{L^{1}}{\lambda^{1}}\right)+\left(p^{1 A} F_{K L}^{1} \dot{L}^{1} k+p^{1 A} F_{L L}^{1} \dot{L}^{1} \frac{L^{1}}{\lambda^{1}}\right) \\
& \quad+\left(p^{1 A} F_{K K}^{1} \dot{K}^{1} k+p^{1 A} F_{K L}^{1} \dot{K}^{1} \frac{L^{1}}{\lambda^{1}}\right)+t^{1} \dot{M}^{1 A}+M^{1 A} \\
= & \frac{\mathcal{P}^{1 A} F^{1}}{\lambda^{1}}+t^{1} \dot{M}^{1 A}+M^{1 A},
\end{aligned}
$$

where we have used Euler's theorem three times.

$$
\begin{aligned}
\dot{y}^{2 A}= & p^{2 A} F_{K K}^{2} \dot{K}^{2} k+p^{2 A} F_{K L}^{2} \dot{L}^{2} k+t^{1} \dot{M}^{1 A}+M^{1 A} \\
= & p^{2 A} F_{K K}^{2} \dot{K}^{2} k+p^{2 A} F_{K L}^{2} \dot{L}^{2} k+t^{1} \dot{M}^{1 A}+M^{1 A} \\
& \quad+\left(p^{2 A} F_{L L}^{2} \dot{L}^{2} \frac{L^{2}}{\lambda^{2}}-p^{2 A} F_{L L}^{2} \dot{L}^{2} \frac{L^{2}}{\lambda^{2}}\right)+\left(p^{2 A} F_{K L}^{2} \dot{K}^{2} \frac{L^{2}}{\lambda^{2}}-p^{2 A} F_{K L}^{2} \dot{K}^{2} \frac{L^{2}}{\lambda^{2}}\right) \\
= & \left(p^{2 A} F_{K K}^{2} \dot{K}^{2} k+p^{2 A} F_{K L}^{2} \dot{K}^{2} \frac{L^{2}}{\lambda^{2}}\right)+\left(p^{2 A} F_{K L}^{2} \dot{L}^{2} k+p^{2 A} F_{L L}^{2} \dot{L}^{2} \frac{L^{2}}{\lambda^{2}}\right) \\
& \quad-\left(p^{2 A} F_{L L}^{2} \dot{L}^{2} \frac{L^{2}}{\lambda^{2}}+p^{2 A} F_{K L}^{2} \dot{K}^{2} \frac{L^{2}}{\lambda^{2}}\right)+t^{1} \dot{M}^{1 A}+M^{1 A} \\
= & t^{1} \dot{M}^{1 A}+M^{1 A},
\end{aligned}
$$

using Euler's theorem two times.

Finally, recall that there is no income from a state $A$ contingent tariff in states $B$ or $C$. Thus, in states $B$ and $C, y^{i s}=w+r^{i s} k$. Hence 


$$
\dot{y}^{i s}=p^{i s} F_{K L}^{i} k \dot{L}^{i}+p^{i s} F_{K K}^{i} \dot{K}^{i} k=0, \quad s=B, C
$$

by Euler's theorem.

Q.E.D.

Proposition 2 A small state contingent sector specific tariff increases welfare; i.e.,

$$
\left.\frac{\partial W}{\partial t^{i s}}\right|_{t^{i s}=0}>0
$$

Proof: As above, we will proceed by analyzing a state $A$ contingent tariff. Recall that

$$
\frac{\partial V^{i A}}{\partial t^{1}}=V_{y}^{i A} \dot{y}^{i}+V_{1}^{i A} \mathcal{P}^{1 A}, \quad i=1,2
$$

and that

$$
\begin{aligned}
& M^{1 A}-\mathcal{P}^{1 A} C^{11 A}=\mathcal{P}^{1 A}\left(\lambda^{2}\left(C^{12 A}-C^{11 A}\right)-F^{1}\right) \\
& M^{1 A}-\mathcal{P}^{1 A} C^{12 A}=\mathcal{P}^{1 A}\left(\lambda^{1}\left(C^{11 A}-C^{12 A}\right)-F^{1}\right)
\end{aligned}
$$

Using Lemmas 3 and 4 we have

$$
\begin{aligned}
\left.\frac{\partial W^{A}}{\partial t^{1}}\right|_{t^{1}=0} & =\lambda^{1} \frac{\partial V^{1 A}}{\partial t^{1}}+\lambda^{2} \frac{\partial V^{2 A}}{\partial t^{1}} \\
& =\lambda^{1}\left(V_{y}^{1 A} \dot{y}^{1}+V_{1}^{1 A} \mathcal{P}^{1 A}\right)+\lambda^{2}\left(V_{y}^{2 A} \dot{y}^{2}+V_{1}^{2 A} \mathcal{P}^{1 A}\right) \\
& =\lambda^{1} V_{y}^{1 A}\left(\dot{y}^{1}-\mathcal{P}^{1 A} C^{11 A}\right)+\lambda^{2} V_{y}^{2 A}\left(\dot{y}^{2}-\mathcal{P}^{1 A} C^{12 A}\right) \\
& =\lambda^{1} V_{y}^{1 A}\left(\mathcal{P}^{1 A} F^{1} / \lambda^{1}+M^{1 A}-\mathcal{P}^{1 A} C^{11 A}\right)+\lambda^{2} V_{y}^{2 A}\left(M^{1 A}-\mathcal{P}^{1 A} C^{12 A}\right) \\
& =\lambda^{1} V_{y}^{1 A} \mathcal{P}^{1 A}\left(F^{1} \lambda^{2} / \lambda^{1}+\lambda^{2}\left(C^{12 A}-C^{11 A}\right)\right)+\lambda^{2} V_{y}^{2 A} \mathcal{P}^{1 A}\left(\lambda^{1}\left(C^{11 A}-C^{12 A}\right)-F^{1}\right) \\
& =\mathcal{P}^{1 A} F^{1} \lambda^{2}\left(V_{y}^{1 A}-V_{y}^{2 A}\right)+\mathcal{P}^{1 A} \lambda^{1} \lambda^{2}\left(C^{12 A}-C^{11 A}\right)\left(V_{y}^{1 A}-V_{y}^{2 A}\right)>0
\end{aligned}
$$

The last expression is positive. To see this, note that $y^{1 A}<y^{2 A}$; hence the first term in the right hand side is positive because of diminishing marginal utility of income. The second term is positive because whether or not $y^{2}>y^{1}$, the terms $C^{12 A}-C^{11 A}$ and $V_{y}^{1 A}-V_{y}^{2 A}$ always have the same sign.

The only remaining step is to show that $d W^{s} / d t^{1}=0$ for $s=B, C$. But this is simple enough, since we have shown in Lemma 3 that $\dot{y}^{i s}=0, i=1,2$ for all states $s=B, C$. Since a state $A$ contingent tariff has no direct effect on prices in the other states it follows that 


$$
\frac{\partial V^{i s}}{\partial t^{1}}=V_{y}^{i s} \dot{y}^{i s}+\sum_{i} V_{y}^{i s} \frac{\partial p^{1 s}}{d t^{1}}=0, \quad i=1,2, s=B, C
$$

Q.E.D.

\section{Specific taxes and subsidies}

An alternative policy instrument are specific taxes and subsidies to the sectors. We consider an ad valorem production subsidy $\sigma^{i s}$ to sector $i$ in state $s$. To fix ideas, producers receive price $p^{i s}=\left(1+\sigma^{i s}\right) \mathcal{P}^{i s}$ where

$$
\sigma^{i s}= \begin{cases}\sigma^{i}>0 & \text { if } i=1 \text { and } s=A \text { or if } i=2 \text { and } s=B \\ 0 & \text { otherwise. }\end{cases}
$$

In other words, producers in sector $i$ only receive the subsidy when $i$ receives a negative shock. We assume that consumers continue to face world prices and that the subsidy is paid by lump sum taxation, so that taxes in sector $i$ are $\tau^{i s} \equiv \lambda^{i} \sigma^{i s} \mathcal{P}^{i s} F^{i s}$.

Consider for instance when state $A$ is realized and sector 1 receives the negative price shock. In the rest of the section we will we omit the superscript denoting the state unless doing so leads to confusion. Let $\rho^{1} \equiv \mathcal{P}^{1} F^{1}$; therefore the total value of the subsidy is $\sigma^{1} \rho^{1}$. The income received by type $i$ household is

$$
y^{i}=w+p^{i} F_{K}^{i} k-\lambda^{i} \sigma^{i} \rho^{i}, \quad i=1,2 .
$$

Using hat notation to denote derivatives with respect to the subsidy to sector 1 (i.e., $\hat{y} \equiv d y / d \sigma^{1}$, we can show

Lemma 5 The change in income due to a state $A$ contingent subsidy cum tax is

$$
\begin{aligned}
& \hat{y}^{1}=\frac{\rho^{1}}{\lambda^{1}}+\lambda^{2}\left(\sigma^{1} \hat{\rho}^{1}+\rho^{1}\right)+\hat{\lambda}^{2} \sigma^{1} \rho^{1} \\
& \hat{y}^{2}=-\lambda^{2}\left(\sigma^{1} \hat{\rho}^{1}+\rho^{1}\right)-\hat{\lambda}^{2} \sigma^{1} \rho^{1}
\end{aligned}
$$

Proof: Differentiating (13)

$$
\begin{aligned}
& \hat{y}^{1}=\mathcal{P}^{1} F_{K}^{1} k+p^{1} F_{K K}^{1} \hat{K}^{1} k+p^{1} F_{K L}^{1} \hat{L}^{1} k+\lambda^{2}\left(\sigma^{1} \hat{\rho}^{1}+\rho^{1}\right)+\hat{\lambda}^{2} \sigma^{1} \rho^{1}, \\
& \hat{y}^{2}=\mathcal{P}^{2} F_{K K}^{2} \hat{K}^{2} k+\mathcal{P}^{2} F_{K L}^{2} \hat{L}^{2} k-\lambda^{2}\left(\sigma^{1} \hat{\rho}^{1}+\rho^{1}\right)-\hat{\lambda}^{2} \sigma^{1} \rho^{1} .
\end{aligned}
$$


Adding and subtracting $p^{i} F_{K L}^{i} \hat{K}^{i}\left(L^{i} / \lambda^{i}\right)$ and $p^{i} F_{L L}^{i} \hat{L}^{i}\left(L^{i} / \lambda^{i}\right)$, using the fact that $\hat{w}=0$ and using Euler's theorem gives the desired expression.

Q.E.D.

Recall that consumers face world prices, so the subsidy does not change the prices they face. Hence $d V^{i} / d \sigma^{1}=V_{y}^{i} \hat{y}^{i}$, and the total change in welfare in state $A$ due to a small contingent production subsidy is

$$
\begin{aligned}
\left.\frac{d W^{A}}{d \sigma^{1}}\right|_{\sigma^{1}=0} & =\lambda^{1} V_{y}^{1}\left(\frac{\rho^{1}}{\lambda^{1}}+\lambda^{2} \rho^{1}\right)-V_{y}^{2} \lambda^{2} \rho^{1} \\
& =\left(\left(1+\lambda^{1} \lambda^{2}\right) V_{y}^{1}-\lambda^{2} V_{y}^{2}\right) \mathcal{P}^{1} F^{1}>0
\end{aligned}
$$

Note also that $d W^{B} / d \sigma^{1}=0$, as in the previous section. The negative shock implies that $V_{y}^{1 A}>$ $V_{y}^{2 A}$ and hence the effect of the subsidy is always positive. Hence we have that

Proposition 3 A small state contingent subsidy is welfare improving; i.e.,

$$
\left.\frac{\partial W}{\partial \sigma^{i s}}\right|_{\sigma^{i s=0}}>0
$$

\section{Conclusions and Extensions}

Using a general equilibrium model with incomplete insurance markets, we have shown that contingent protection on a sectoral basis will increase welfare when the economy is subject to sector specific price shocks. Our model thus provides theoretical basis for the long held notion that GATT exceptions can act as insurance. Trade negotiators have long argued that the inclusion of the most popular sector specific tool-antidumping actions - is a pre-condition for the approval of any trade agreement. The main result of the paper affirms this intuition by showing that there is an insurance role for antidumping that had not been considered in the theoretical literature.

We also show that there exist alternative instruments that also lead to improvements in welfare, such as a set of lump sum taxes on all sectors coupled to a subsidy to the sector that receives the shock. However, we believe there are two reasons why taxes and subsidies are not generally used as insurance against price shocks. First, political economy reasons which make the imposition of selective taxes non-attractive. Second, over the past twenty years there is considerable support for the view that antidumping regulations have been captured by protectionist interests (Bhagwati, 1988; Krueger, 1995). Hence, from a protectionist viewpoint, the value of antidumping regulations lies not only in its insurance aspects, but also in the fact that it can be manipulated.

One limitation of this paper is that it does not show why exceptions are needed in order to sign trade agreements. If protection is what is desired, why is that not included in the original 
agreements? Another caveat is that out results should be interpreted as second best arguments for

contingent protection. As a first best, policy should always be directed at removing the sources of distortion, if possible.

\section{References}

Baldwin, R.E. (1982) "The political economy of protectionism," in J.N. Bhagwati (ed.), Import Competition and Response, (Chicago: University of Chicago Press).

Bhagwati, Jagdish, 1988, Protectionism, (Cambridge: MIT Press).

Dam, K.W. (1970) The GATT: Law and International Economic Organization, (Chicago: University of Chicago Press)

Corden, W.M. (1974) Trade Policy and Economic Welfare, (Oxford: Oxford University Press).

Dixit, A.K. (1987) "Trade and insurance with moral hazard," Journal of International Economics (23), 201-220.

Dixit, A.K. (1989a) "Trade and insurance with adverse selection," Review of Economic Studies (56), 235-248.

Dixit, A.K. (1989b) "Trade and insurance with imperfectly observed outcomes," Quarterly Journal of Economics.

Eaton, J. and Grossman, G.M. (1985): "Tariffs as Insurance: optimal Commercial policy when Domestic Markets are Incomplete," Canadian Journal of Economics (18)2, 258-272.

Ethier, W. (1982): "Dumping,” Journal of Political Economy, (90), 487-506.

Finger, J.M., ed. (1993) Antidumping: How it works and who gets hurt, (Ann Arbor: University of Michigan Press).

Hansen, W. and Prusa, T.J. (1994): "The Road most Taken: The Rise of Title VII Protection," The World Economy, 295-313.

Jackson, J. (1969) World trade and the law of GATT, (New York: Bobbs-Merrill Co., Inc.).

Krueger, A.O., 1995, The American trade policy: A tragedy in the making, (Washington, D.C.: The AEI Press).

Staiger, R.W. and Tabellini, G. (1987): "Discretionary Trade policy and Excessive Protection," American Economic Review (77), 823-837.

Staiger, R.W. (1995) "International rules and institutions for trade policy," in G.M. Grossman and K. Rogoff (eds.) Handbook of International Economics Volume 3, (Amsterdam: NorthHolland). 
Staiger, R.W. and Frank A. Wolak (1994) Measuring Industry Specific Protection: Antidumping in the United States, Brookings Papers on Economic Activity, Microeconomics, 51-103. 